\title{
PIXE Analysis of Persian Miniature Used in 16th Century Poetry Manuscript
}

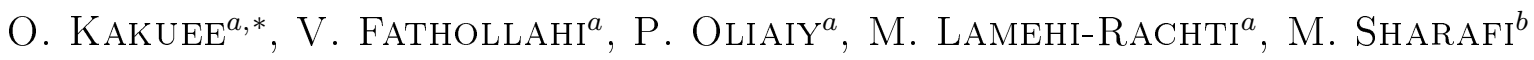 \\ AND M.B. KASIRI ${ }^{b}$ \\ ${ }^{a}$ Nuclear Science Research School, NSTRI, P.O. Box 14395-836, Tehran, Iran \\ ${ }^{b}$ Department of Applied Chemistry, Faculty of Chemistry, University of Tabriz, Tabriz, Iran
}

(Received January 29, 2014)

\begin{abstract}
In Persian culture, precious poetry manuscripts used to be decorated by miniature paintings and illuminations to visualize the story of the poem to the reader. The Joseph and Zulaikha story written in Persian by Jami (14141492 ) is one of the poetry books which has attracted considerable attention and has been copied and decorated by calligraphers and painters several times. This paper will focus on characterization of Persian miniature of the Joseph and Zulaikha created in the 15th-16th century in the Bokhara school. To collect the required information for preservation, restoration, and authenticity of the masterpiece, the elemental composition of the applied pigments in the miniature paintings as well as the elemental composition of the employed ink and paper was analyzed by external PIXE.
\end{abstract}

DOI: $10.12693 /$ APhysPolA.125.1244

PACS: $82.80 . \mathrm{Ej}, 07.85 . \mathrm{Nc}$

\section{Introduction}

Miniature paintings and illuminations were used to be added to the great poetry books in ancient Iran to make them more pleasant, enjoyable and easier to understand. In fact, miniature developed into a marriage of artistic and poetic languages and obtained a deep and sincere accordance with poetry. To reveal the technical features of this art and also to conserve and restore such artefacts, precise analysis of applied materials in the paintings and illuminations is necessary [1]. Since IBA techniques are non-destructive, fast, sensitive and multi-elemental, they are well-suited for analysis of objects and monuments of culturo-historical value $[2,3]$. The application of ion beam analysis for characterization of culturo-historical artefacts was initialized after development of the PIXE technique in the early seventies. Dedicated ion beam analysis facilities and beamlines were later setup in different laboratories such as the ALGAE accelerator in Louvre museum [4], the $5 \mathrm{MV}$ tandetron accelerator laboratory in Madrid [5] and the $3 \mathrm{MV}$ tandem accelerator in Firenze [6] for analysis of cultural heritage items. To satisfy the same requirements in Iran, a dedicated beamline in Van de Graaff lab in Tehran is recently developed for ion beam analysis of culturo-historical samples [7].

Persia region historically was conquered again and again by different cultures. All of those cultures left their mark on Persian painting. One of them was the Ozbaks, descendants of Shibān, grandson of Changiz, considered Khorāsān and Transoxiana in 16th century. The Bokhara

*corresponding author; e-mail: okakuee@yahoo.com style of painting is formed as a consequence of this occupation [8].

The miniature paintings of the Joseph and Zulaikha poetry manuscript - now preserved in the Institute for Iranian Contemporary Historical Studies (IICHS) with registration number of 1259 - are subject of this study.

According to the renowned contemporary bibliographer, N. Mayel Heravi, the investigated masterpiece belongs to the Bokhara school [9].

The Bokhara style is marked by an underlying grayish tone visible in the blues, greens, and pinks [8]. With this in mind, by applying external PIXE analysis we tried to identify elemental composition of the pigments used for blue, green, and pink colors of this masterpiece to conclude the most commonly applied pigments employed in the above style.

\section{Materials and methods}

The subject of this study is a 56-page masterpiece created in 16 th century, which includes 5 full-page miniature paintings in $200 \times 300 \mathrm{~mm}^{2}$ in the Bokhara School. In this school, a number of well-known decorated manuscripts are created such as Mehr-o Moshtari which is preserved in the Freer Gallery of Art, Washington, D.C. It is perhaps the earliest dated example of the Herat style produced in Bokhara in 1523. Among other manuscripts illuminated in the Bokhara school, one could name the Haft manzar (Seven belvederes) by the poet Hatefi (Freer Gallery of Art, Washington, D.C.), copied in Bokhara in 1537 and the magnificent Bustan copied about 1540-45 (Harvard University Art Museums, Cambridge) [8].

The external PIXE analysis was carried out using the facilities of Van de Graff Lab in Tehran. To analyze the 
details of interest in the sample, a $2200 \mathrm{keV}$ of proton beam of about $1 \mathrm{~mm}$ diameter was irradiated to 22 points of the artwork. To accelerate the process of analyzing the points of interest, an $x-y$ stage which is linked to our programmable data acquisition system, precisely moves the sample support and exposes the points of interest to the analyzing probe. The X-ray spectra were collected by a $\mathrm{Si}(\mathrm{Li}) \mathrm{X}$-ray detector placed at a scattering angle of $135^{\circ}$ and $20 \mathrm{~mm}$ from the beam-target intersection. In this setup the beam charge is indirectly measured through the $\operatorname{Ar} K_{\alpha}$ X-ray yield originated from radiation of in-air argon by protons in the beam path. More experimental details are explained in our previous work [1]. The elemental composition of different pigments used in the miniature paintings as well as that of the applied ink and paper in the masterpiece are reported.

\section{Results and discussion}

In this work, 5 pages of the masterpiece were studied. The first page is illuminated starting page named sample M1 (Fig. 1). The next four pages are full page miniatures named M2 to M5 and illustrated in Fig. 2 to Fig. 5, respectively. A total number of 22 spectra were collected from illumination, miniatures, ink and paper. The relative elemental concentrations of each investigated point are outlined in Table.

TABLE

Normalized concentration of different elements present in closely matched colored areas in the miniature paintings (the concentrations of the characteristic elements of pigments are highlighted in bold).

\begin{tabular}{|c|c|c|c|c|c|c|c|c|c|c|c|c|}
\hline $\begin{array}{l}\text { Investigated } \\
\text { points }\end{array}$ & Color & $\mathrm{Si}$ & $\mathrm{P}$ & S & $\mathrm{Cl}$ & $\mathrm{K}$ & $\mathrm{Ca}$ & $\mathrm{Fe}$ & $\mathrm{Cu}$ & As & $\mathrm{Pb}$ & Other elements \\
\hline $\mathrm{B}$ & green & 1277 & 132 & 374 & 36 & 16 & 40 & 4 & 93 & 31 & 71 & $\mathrm{Zn}(14), \mathrm{Cr}(2)$ \\
\hline $\mathrm{F}$ & green & 1397 & 91 & 674 & 39 & 13 & 47 & 19 & 341 & 0 & 429 & $\mathrm{Ba}(6), \mathrm{Zn}(3), \mathrm{Au}(10), \mathrm{Cr}(4)$ \\
\hline G & green & 1888 & 426 & 818 & 35 & 13 & 48 & 19 & 346 & 0 & 420 & $\mathrm{Ba}(5), \mathrm{Zn}(4), \mathrm{Au}(7), \mathrm{Cr}(4)$ \\
\hline $\mathrm{H}$ & green & 1080 & 218 & 926 & 29 & 9 & 132 & 3 & 2 & 18 & 236 & $\operatorname{Cr}(5)$ \\
\hline I & green & 1119 & 180 & 656 & 32 & 12 & 89 & 5 & 3 & 29 & 180 & $\mathrm{Cr}(3)$ \\
\hline M & green & 2894 & 89 & 91 & 24 & 14 & 30 & 25 & 818 & 0 & 52 & $\mathrm{Zn}(7)$ \\
\hline $\mathrm{O}$ & green & 872 & 52 & 848 & 40 & 17 & 129 & 40 & 3 & 66 & 149 & $\operatorname{Cr}(6)$ \\
\hline $\mathrm{Q}$ & green & 4025 & 618 & 2636 & 43 & 18 & 501 & 32 & 3 & 11 & 583 & $\operatorname{Mn}(6), \operatorname{Cr}(17)$ \\
\hline $\mathrm{A}$ & blue & 7848 & 146 & 795 & 47 & 27 & 14 & 3 & 4 & 0 & 136 & \\
\hline $\mathrm{C}$ & blue & 4002 & 129 & 625 & 42 & 23 & 24 & 5 & 0 & 0 & 384 & $\mathrm{Cr}(1)$ \\
\hline $\mathrm{D}$ & blue & 1337 & 25 & 683 & 34 & 12 & 20 & 7 & 180 & 0 & 374 & $\mathrm{Cr}(1)$ \\
\hline $\mathrm{E}$ & blue & 3732 & 133 & 604 & 40 & 24 & 24 & 7 & 1 & 0 & 196 & $\mathrm{Au}(2), \mathrm{Cr}(1)$ \\
\hline $\mathrm{K}$ & blue & 4238 & 224 & 1077 & 41 & 26 & 21 & 10 & 2 & 3 & 585 & \\
\hline $\mathrm{N}$ & blue & 3678 & 246 & 567 & 26 & 17 & 18 & 4 & 1 & 0 & 1058 & \\
\hline $\mathrm{L}$ & pink & 4043 & 383 & 1502 & 95 & 18 & 23 & 16 & 281 & 0 & 1285 & $\mathrm{Zn}(2)$ \\
\hline $\mathrm{U}$ & pink & 1661 & 204 & 388 & 41 & 9 & 19 & 4 & 1 & 0 & 372 & $\mathrm{Hg}(49)$ \\
\hline $\mathrm{R}$ & yellow & 1317 & 126 & 10 & 34 & 20 & 15 & 4 & 1 & 0 & 6 & $\mathrm{Hg}(1), \mathrm{Au}(96)$ \\
\hline S & yellow & 1295 & 108 & 23 & 23 & 17 & 11 & 4 & 1 & 0 & 0 & $\mathrm{Au}(198)$ \\
\hline $\mathrm{P}$ & black & 2473 & 195 & 333 & 55 & 22 & 28 & 0 & 1 & 0 & 178 & $\operatorname{Mn}(7), \operatorname{Au}(1)$ \\
\hline $\mathrm{W}$ & ink & 698 & 55 & 23 & 22 & 19 & 16 & 7 & 0 & 0 & 0 & \\
\hline $\mathrm{V}$ & paper & 630 & 42 & 32 & 42 & 14 & 12 & 2 & 0 & 0 & 0 & \\
\hline $\mathrm{T}$ & damaged & 650 & 127 & 337 & 22 & 3 & 24 & 3 & 6 & 0 & 754 & $\mathrm{Ba}(3), \mathrm{Cr}(2)$ \\
\hline $\mathrm{J}$ & brown & 1676 & 121 & 549 & 40 & 13 & 13 & 5 & 1 & 0 & 347 & \\
\hline
\end{tabular}

To identify the characteristic elements of pigments applied for preparing specifically colors in the Bokhara style miniatures, i.e. blue, green, and pink, each point of interest was analyzed by energetic proton beam. Analysis of different colored points is outlined as follows.

\subsection{Green pigments}

The investigated green colored points listed in Table could be classified in two distinct categories. The first category including points E, F (marked with arrow in Fig. 2) and M (marked in Fig. 4) are copper-based greens whose origin is either malachite [10], a naturally occurring copper ore, or verdigris. The second category including points B, H, I, O, and Q (marked in Figs. 2, 3, $3,4,5$, respectively) do not show any copper content, but arsenic was measured as their characteristic element in their PIXE spectra. It seems that arsenic sulfide and indigo were mixed to form the pigments of these green 


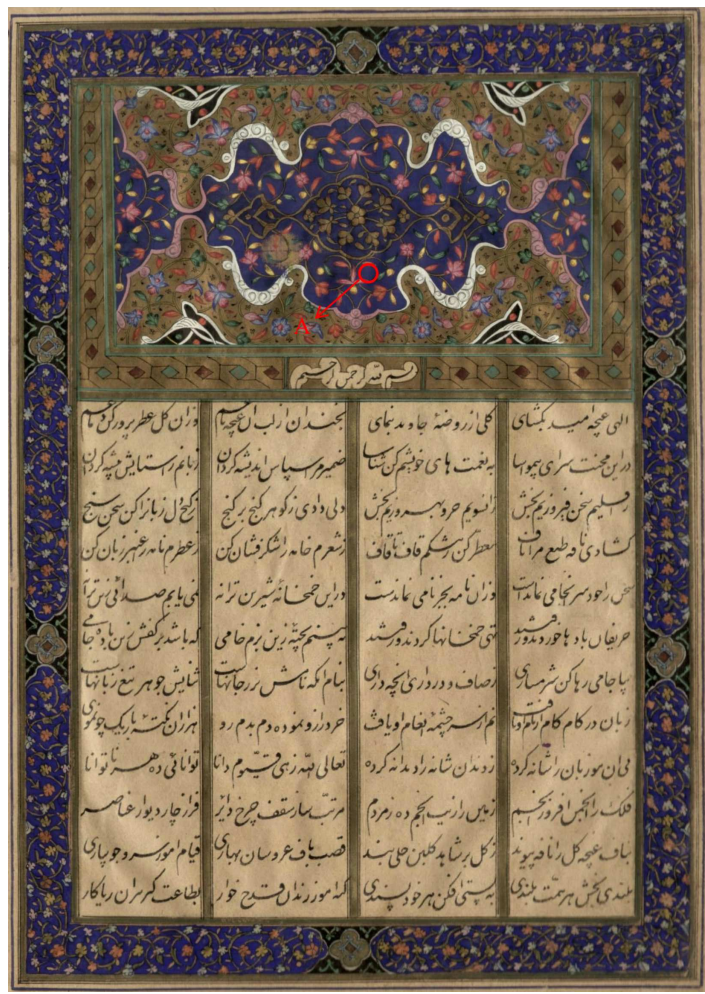

Fig. 1. Starting page of the masterpiece (sample M1) with an illumination in the top and handwritten poems in the rest of the page. The investigated blue point is marked with an arrow.

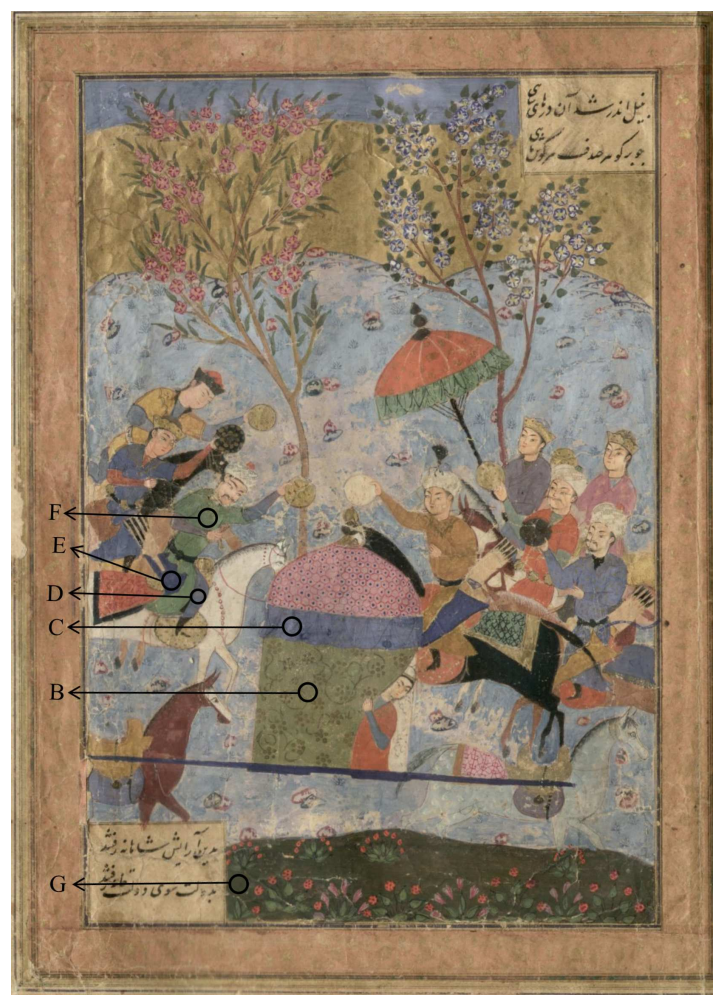

Fig. 2. The 1st miniature of the masterpiece in which 6 marked points in green and blue are investigated.

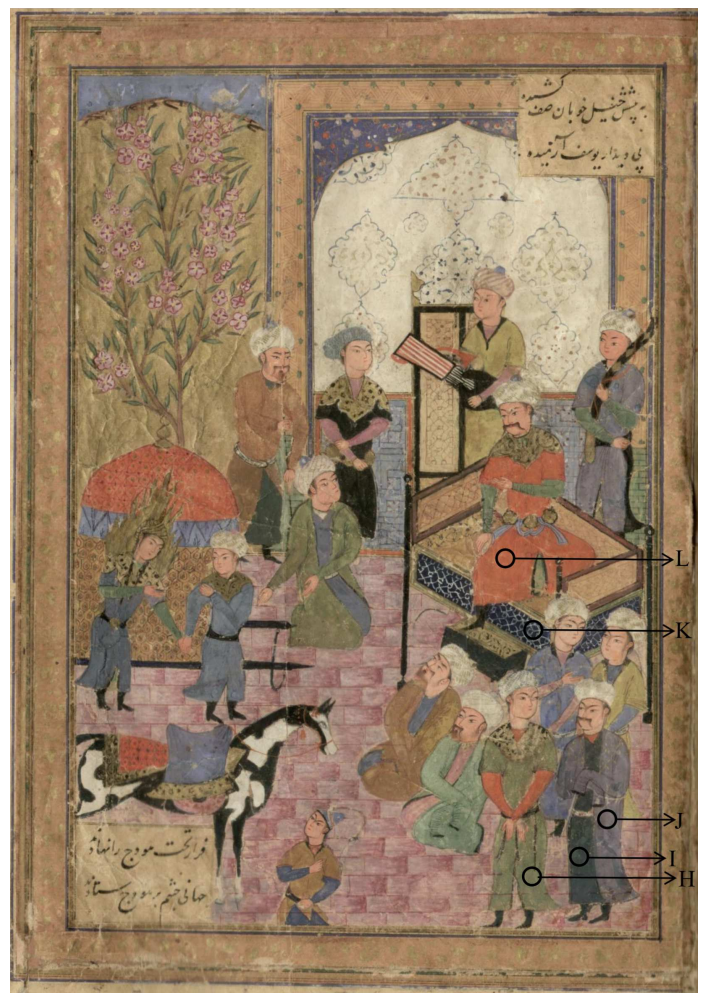

Fig. 3. The 2nd miniature of the masterpiece in which 5 marked points in green, blue, and pink are investigated.

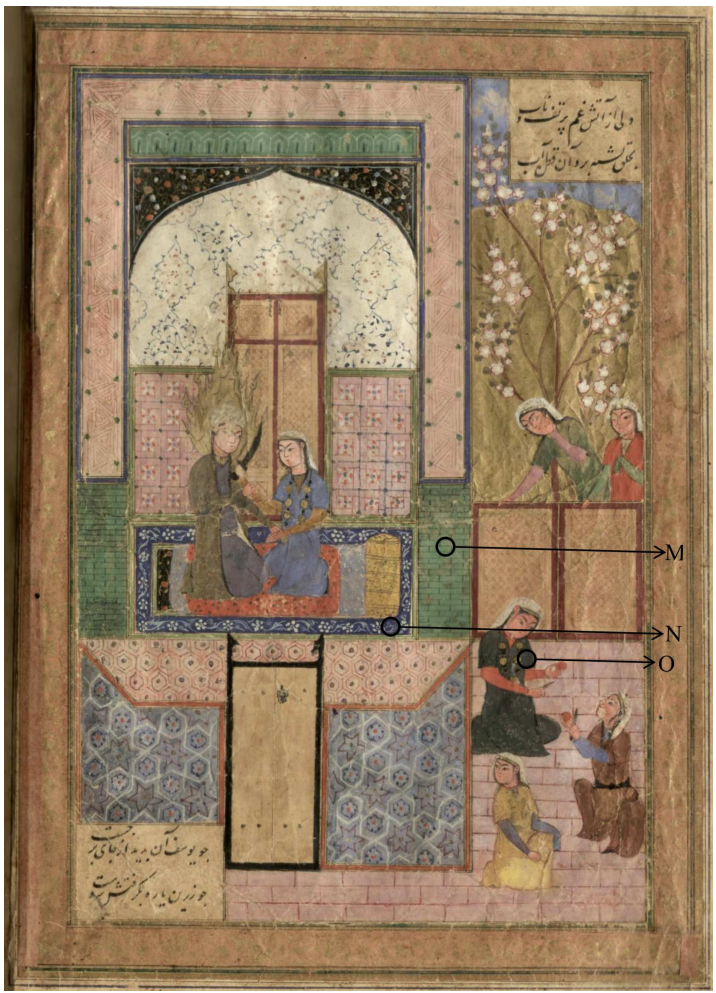

Fig. 4. The 3rd miniature of the masterpiece in which 3 marked points in green and blue are investigated. 


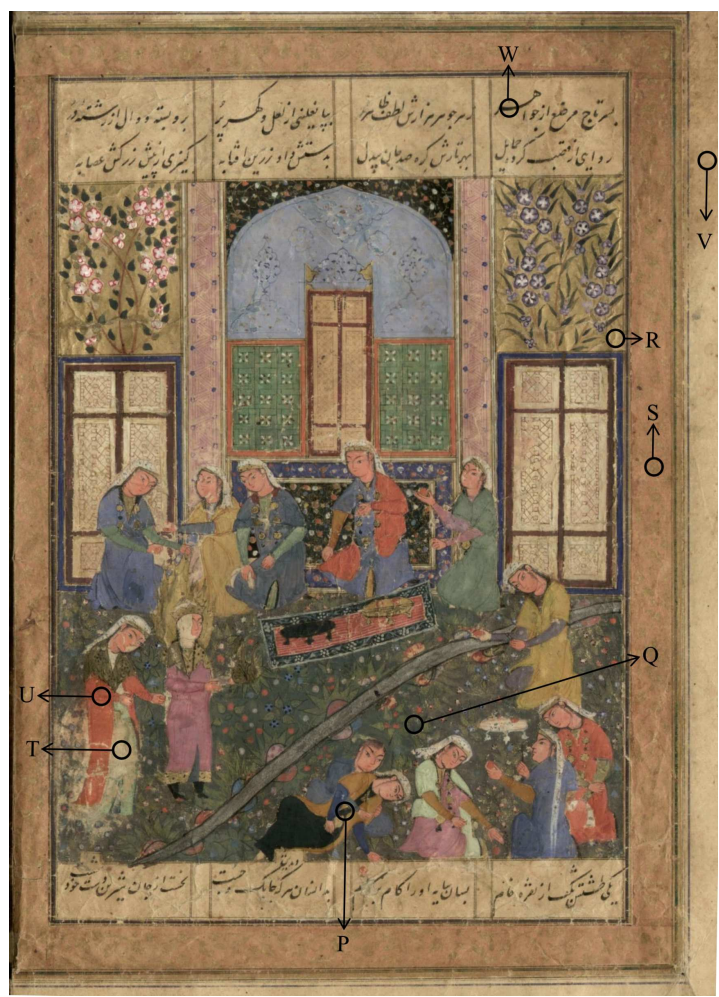

Fig. 5. The 4th miniature of the masterpiece in which 8 marked points in blue, green, yellow, and pink as well as paper and ink are investigated.

colored regions. PIXE spectra of green-colored points $\mathrm{F}$ (copper-based green) and B (arsenic-based green) which are normalized based on $\operatorname{Ar} K_{\alpha}$ intensity are compared in Fig. 6.

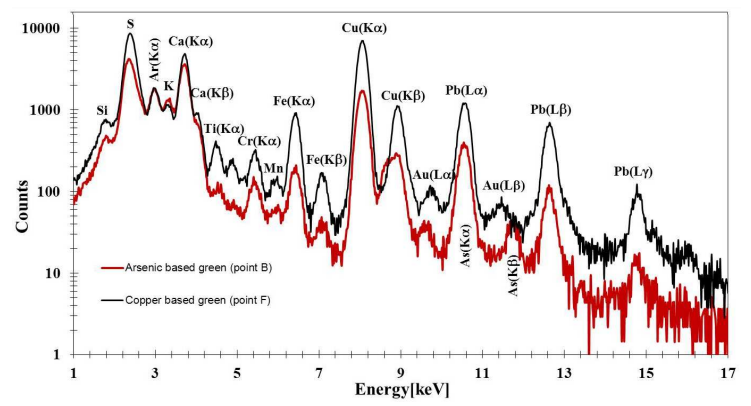

Fig. 6. Comparison of PIXE spectra of green-colored points B (arsenic-based green) and F (copper-based green) which are normalized based on Ar $K_{\alpha}$ intensity.

It is worth to mention that indigo was used in ancient Iran as the origin of blue color [11-13]. This pigment seems to be applied for painting of the region around point $\mathbf{J}$ (marked in Fig. 3) in sample M3. In point $\mathrm{Q}$ of sample M5, it seems that the painter added some gypsum (with characteristic elements of $\mathrm{Ca}$ and $\mathrm{S}$ ) and silicate (with characteristic element of $\mathrm{Si}$ ) to create bright green leaves in the green background of this region.

\subsection{Blue pigments}

Due to elemental composition of blue colored points $\mathrm{C}$, $\mathrm{E}, \mathrm{K}$ and $\mathrm{N}$ (marked in Figs. 2, 2, 3, 4 respectively), it can be concluded that the origin of these colors is lazurite pigment. As it can be seen in the point $\mathrm{N}$ of sample M4 and due to the rather large proton beam spot size $\left(>1 \mathrm{~mm}^{2}\right)$, the white colored flowers are more likely contributed in the PIXE spectrum of this point. Therefore, the considerable lead content in PIXE spectrum of this point originates from lead white pigment applied for painting of these flowers. Moreover to create the blue color of point D (marked in Fig. 2), it seems that the painter added a small amount of copper based green pigment with indigo. This is why copper is observed as the characteristic element of this point. PIXE spectra of blue-colored points E (blue color with origin of lazurite) and D (created by mixing copper-based green with indigo) which are normalized based on $\operatorname{Ar} K_{\alpha}$ intensity are compared in Fig. 7.

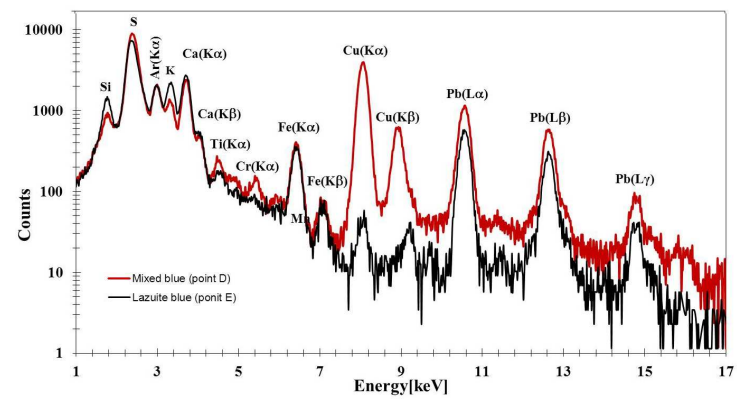

Fig. 7. Comparison of PIXE spectra of blue-colored points D (created by mixing copper-based green with indigo) and $\mathrm{E}$ (blue color with origin of lazurite) which are normalized based on $\operatorname{Ar} K_{\alpha}$ intensity.

Due to the paper material and quality of the paintings and the hand written text in sample M1, it seems that this sample is renewed within the last few decades. Based on the elemental composition of point A (marked in Fig. 1) in this sample, it can be concluded that this blue colored region is painted using synthetic lazurite pigment [9].

\subsection{Pink pigments}

The presence of mercury characteristic element in the elemental composition of pink-colored point $U$ (marked in Fig. 5) of sample M5 indicates that this color is originating from cinnabar pigment, which was traditionally used for making red color in ancient Iran [12]. The investigated pink-colored point L (marked in Fig. 3) of sample M3 has a different elemental composition including lead, copper, iron, silicon, and sulfur. The light pink of this point suggests that a little bit of green pigment malachite is added to the main minium [1] pigment. In addition the painter added an extra material with characteristic elements of silicon and sulfur for painting of this color. The 
same material is used as a complementary composition for painting of point $\mathrm{K}$ (marked in Fig. 3) in sample M3.

\subsection{Yellow}

The elemental composition of yellow points $\mathrm{R}$ and $\mathrm{S}$ (marked in Fig. 5) in miniature M5 reveals the use of gold in decoration and painting of this miniature. In fact, the use of gold for painting of valuable royal miniature was still continued in this style as a traditional practice [1].

\subsection{Black and ink}

It is evident that the black color of point $\mathrm{P}$ (marked in Fig. 5) in sample M5 is originating from pyrolusite pigment whose characteristic element is $\mathrm{Mn}$ [13]. Moreover, the black color of ink used in the text of sample M5 (point W marked in Fig. 5) originates from typical carbon-based inks, which do not contain any characteristic elements.

$$
\text { 3.6. Paper }
$$

Presence of different elements such as Si, P, S, Cl, K, and $\mathrm{Ca}$ in the PIXE spectrum of paper, along with the results of complementary investigations such as optical microscopy confirms that the applied paper is made of cotton fibers [9].

\section{Conclusion}

Miniature paintings, ink and paper of Yusuf and $\mathrm{Zu}-$ likha - a great hand written poetry book of 16 th century - were analyzed by external PIXE. Elemental concentrations of selected colored points revealed that:

- The green colors of the miniatures are either copper-based green or are produced as a combination of arsenic sulfide and indigo.

- The blue colors of the miniatures are either lazurite or are formed by combination of copper based green with indigo.

- The pink colors of the miniatures are either cinnabar or are formed by combination of a little bit malachite with minium.

Moreover, the pigment of black color was found to be originated from pyrolusite pigment and gold was used for decoration of the miniatures.

\section{References}

[1] O. Kakuee, V. Fathollahi, P. Oliaiy, M. LamehiRachti, R. Taheri, H.A. Jafarian, Nucl. Instrum. Methods Phys. Res. B 273, 178 (2012).

[2] L. Beck, L. Pichon, B. Moignard, T. Guillou, P. Walter, Nucl. Instrum. Methods Phys. Res. B 269, 2999 (2011).

[3] A. Zucchiatti, F. Agullo-Lopez, Nucl. Instrum. Methods Phys. Res. B 278, 106 (2012).
[4] T. Calligaro, J.-C. Dran, E. Ioannidou, B. Moignard, L. Pichon, J. Salomon, Nucl. Instrum. Methods Phys. Res. B 161-163, 328 (2000).

[5] O. Enguita, M.T. Fernandez-Jimenez, G. Garcia, A. Climent-Font, T. Calderon, G.W. Grime, Nucl. Instrum. Methods Phys. Res. B 219-220, 384 (2004).

[6] L. Giuntini, M. Massi, S. Calusi, Nucl. Instrum. Methods Phys. Res. A 576, 266 (2007).

[7] M. Torkiha, M. Lamehi-Rachti, O.R. Kakuee, V. Fathollahi, Nucl. Instrum. Methods Phys. Res. B 268, 1517 (2010).

[8] A. Soudavar, Art of the Persian Courts, Rizzoli, New York 1992

[9] M. Sharafi, M.Sc. Thesis, Islamic Azad University, Tehran 2011.

[10] P. Vandenabeele, L. Moens, in: Comprehensive Analytical Chemistry, Vol. 42, Eds. K. Janssens, R. Van Grieken, Elsevier, Amsterdam 2004, p. 644.

[11] S. Ahmadi, F. Shokouhi, P. Oliaiy, M. Lamehi-Rachti, J. Rahighi, Int. J. PIXE 15, 345 (2005).

[12] D. Agha-Aligol, F. Khosravi, M. Lamehi-Rachti, A. Baghizadeh, P. Oliaiy, F. Shokouhi, Appl. Phys. A 89, 799 (2007).

[13] R.J.H. Clark, C.R. Chimie 5, 7 (2002). 